\title{
Fusion-bonded epoxy composite coatings on chemically functionalized API steel surfaces for potential deep-water petroleum exploration
}

\author{
Patrícia A. Saliba, Alexandra A. Mansur, Dagoberto B. Santos and Herman S. Mansur * (1)
}

\author{
*Correspondence: \\ hmansur@demet.ufmg.br \\ Center of Nanoscience, \\ Nanotechnology \\ and Innovation-CeNano2I, \\ Department of Metallurgical \\ and Materials Engineering, \\ Federal University of Minas \\ Gerais-UFMG, Av. Antônio \\ Carlos, 6627-Escola de \\ Engenharia, 31.270-901 Belo \\ Horizonte, MG, Brazil
}

\begin{abstract}
Corrosion of oil and gas pipelines significantly reduces the service life of the pipelines, thus increasing costs, and more seriously, it can cause catastrophic environmental accidents. More recently, the exploitation of oil in ultra-deep seawater fields is facing new technological challenges in material selection owing to the extreme production conditions. Thus, the development of organic coatings as protective layers for steel pipelines is of crucial importance against highly corrosive environments. In this work, fusion bonded epoxy (FBE) coatings were deposited onto chemically functionalized carbon steel surfaces with organosilanes to investigate the potential applications in protection against corrosion and degradation in harsh marine environments. Carbon-steel API 5L X42 (American Petroleum Institute Standard grade) was chemically functionalized with two organosilanes, 3-APTES [(3-Aminopropyl)triethoxysilane], and 3-GPTMS [(3-Glycidyloxypropyl)trimethoxysilane], followed by the deposition of FBE composite coatings. The systems were extensively characterized with respect to each component as well as the steel-coating interface. The contact angle measurements and Fourier transform infrared spectroscopy (FTIR) results clearly indicated that the steel surface was effectively modified by the functional amine and glycidyl silane groups, leading to the formation of interfacial covalent bonds with increased hydrophobicity compared to bare steel surfaces. In addition, the morphological and chemical characterizations of FBE by scanning electron microscopy, atomic force microscopy, X-ray diffraction, and FTIR showed that it is composed of an epoxy-based organic matrix of bisphenolA diglycidyl ether (DGEBA) reinforced with uniformly dispersed inorganic phases of calcium silicates and $\mathrm{TiO}_{2}$ particles. Moreover, the chemical functionalization of the steel surfaces with amino and glycidyl silanes significantly altered the interfacial forces with the FBE coatings, resulting in higher adhesion strength for 3-APTES-modified steel compared to 3-GPTMS-steel; however, both mostly showed cohesive rupture mode in the FBE component.
\end{abstract}

Keywords: Coatings, Epoxy composite, Steel protective coating, Fusion-bonded epoxy, Silane functionalization

\section{Springer}

๑) 2015 Saliba et al. This article is distributed under the terms of the Creative Commons Attribution 4.0 International License (http:// creativecommons.org/licenses/by/4.0/), which permits unrestricted use, distribution, and reproduction in any medium, provided you give appropriate credit to the original author(s) and the source, provide a link to the Creative Commons license, and indicate if changes were made. 


\section{Background}

The global oil and gas industry has been developing rapidly owing to the discovery of oil fields at ultra-deep seawater, and this has posed several new challenges for the exploitation and production of petroleum. Materials used in these conditions are subjected to extreme pressure, temperature, and corrosion and the associated technological issues must be addressed with consideration of engineering, economic, and environmental constraints [1-3]. Pipelines for oil transportation that are mainly made of steel have some of the following key advantages: (a) relatively low cost; (b) high efficiency; (c) short construction period; (d) safe and environmentally friendly application; (e) suitability for all global geographies. High-strength low-alloy (HSLA) steels have been widely used for crude oil pipeline transportation in the petroleum industry [1].

API-5L X-type grade steel is one of the most common pipeline materials in the oil industry. They are usually considered as more cost-effective and safer than any other types of steel. However, such pipelines used for the exploitation and transport of oil and gas are usually buried underground, undersea, or immersed in marine salty water, where they can get severely corroded [4-7]. Thus, single or multilayer protective coatings are generally used for external and internal corrosion protection of pipelines in gas/ oil transmission and distribution. The key aspects for corrosion protection are adhesion of the coating to the steel surface, and resistance of the coating to permeation of water, oxygen, and/or ions. Hence, fusion-bonded epoxy (FBE) coatings or a combination of FBE with other materials forming multilayers are widely used for corrosion protection of gas/oil pipelines [8-10]. Epoxy-based polymers such as FBE are the widely used for gas/oil pipelines because they exhibit high chemical resistance, very low permeability to chloride ions, good mechanical flexibility, strong adhesion to steel, and suitable processing characteristics, leading to improved corrosion protection and operational lifetime of the pipelines. However, epoxy coatings can easily absorb moisture, and the diffusion of absorbed water into the epoxy-steel interface owing to the presence of hydrophilic hydroxyl groups in the cured network (epoxy/amine reaction) weakens the interfacial adhesion strength between the epoxy and steel in a corrosive environment, causing system failure $[11,12]$. Thus, the improvement of the adhesion at the steel-epoxy interfaces by using organosilanes primers can be considered an important strategy for inhibiting the corrosion mechanisms. Surprisingly, although there have been a few studies on the use of steel that is chemically modified by silanes for improving the adhesion with epoxy coatings $[13,14]$, no report was found in the consulted literature in which a system composed of steel-primer-FBE was systematically and extensively characterized by considering each individual component and the interfaces between them. Hence, the main goal of this study was to prepare hybrid organic-inorganic FBE coatings using sol-gel chemistry for the functionalization of the steel surfaces to improve the interfacial properties for improved adhesion and protection against corrosion.

\section{Experimental procedure}

Materials

All of the reagents and precursors, (3-Glycidyloxypropyl)trimethoxysilane (3-GPTMS, Aldrich, USA, $\geq 98 \%, \mathrm{C}_{9} \mathrm{H}_{20} \mathrm{O}_{5} \mathrm{Si}$ ), (3-Aminopropyl)triethoxysilane (3-APTES, Aldrich, USA, $99 \%, \mathrm{C}_{9} \mathrm{H}_{23} \mathrm{O}_{3} \mathrm{SiN}$ ), methanol (Synth, Brazil, $99.5 \%, \mathrm{CH}_{4} \mathrm{O}$ ), ethanol (Synth, Brazil, $99.5 \%$, 
$\mathrm{C}_{2} \mathrm{H}_{6} \mathrm{O}$ ), acetic acid (Synth, Brazil, $99.7 \%, \mathrm{C}_{2} \mathrm{H}_{4} \mathrm{O}_{2}$ ), acetone (Synth, Brazil, $99.5 \%, \mathrm{C}_{3} \mathrm{H}_{6} \mathrm{O}$ ), hydrochloric acid (Synth, Brazil, $37 \%, \mathrm{HCl}$ ), sodium hydroxide (Synth, Brazil, $99 \%, \mathrm{NaOH}$ ), and hydrogen peroxide (Synth, Brazil, $29 \%, \mathrm{H}_{2} \mathrm{O}_{2}$ ) were used as received. FBE powder (Scotchkote $^{\mathrm{TM}} 226 \mathrm{~N}, 3 \mathrm{M}^{\mathrm{TM}}$, River Place Blvd., Austin, USA) was used as the coating material. Deionized (DI) water (Millipore Simplicity ${ }^{\mathrm{TM}}$ ) with resistivity of $18 \mathrm{M} \Omega \mathrm{cm}$ was used in the preparation of all solutions. All of the preparations and syntheses were performed at room temperature $\left(25 \pm 2{ }^{\circ} \mathrm{C}\right)$ unless specified otherwise. Potassium bromide (Sigma-Aldrich, USA, $\geq 99 \%, \mathrm{KBr}$ ), suitable for spectroscopy, was used to prepare the FTIR samples.

API-5L X42-PSL2 (Product Specifications Level class\#2) rolled steel plates with thickness of about $9.5 \mathrm{~mm}$ were used as the substrate in all the experimental tests. This steel is commercially available, and its typical chemical composition and mechanical properties are listed in Table 1 [15].

\section{Methods and protocols}

\section{Characterization of steel substrate}

The chemical composition and mechanical properties of the steel plate were supplied by the manufacturer. Microstructural characterizations were carried out using optical microscopy (OM) and scanning electron microscopy (SEM) coupled with energy dispersion X-ray spectroscopy (EDX, EDAX GENESIS). The specimens for the OM and SEM observations were prepared using Nital (2\%) etching solution on the specimen's surface.

Table 1 Chemical and mechanical requirements for API 5L X42 PSL2 steel [15]

\begin{tabular}{|c|c|}
\hline \multicolumn{2}{|l|}{ Chemical composition (\%wt) } \\
\hline Carbon, maximuma & $0.22^{b}-0.24^{c}$ \\
\hline Manganese, maximuma & 1.20 \\
\hline Phosphorus, maximum & 0.025 \\
\hline Sulfur, maximum & 0.015 \\
\hline Titanium, maximum & 0.04 \\
\hline Other $^{d}$ & $\begin{array}{l}\text { By agreement between the purchaser and the manufacturer, } \\
\text { elements other those listed above may be used }\end{array}$ \\
\hline Fe content, balance & Typically >97 \% \\
\hline Carbon equivalent (CE, Pcm), maximum ${ }^{\mathrm{e}}$ & 0.25 \\
\hline Carbon equivalent (CE, IIW), maximum ${ }^{f}$ & 0.43 \\
\hline \multicolumn{2}{|l|}{ Mechanical properties (MPa) } \\
\hline Yield Strength, minimum & 290 \\
\hline Yield Strength, maximum & 496 \\
\hline Ultimate tensile strength, minimum & 414 \\
\hline Ultimate tensile strength, maximum & 748 \\
\hline \multicolumn{2}{|c|}{$\begin{array}{l}\text { For each reduction of } 0.01 \% \text { below the specified maximum carbon content, an increase of } 0.05 \% \text { above the specified } \\
\text { maximum manganese content is permissible, up to a maximum of } 1.50 \%\end{array}$} \\
\hline \multicolumn{2}{|l|}{ b Seamless } \\
\hline \multicolumn{2}{|l|}{ ' Welded } \\
\hline \multicolumn{2}{|c|}{$\begin{array}{l}\text { d Niobium, vanadium, or combinations thereof may be used at the discretion of the manufacturer. The sum of the niobium, } \\
\text { vanadium, and titanium contents shall not exceed } 0.15 \%\end{array}$} \\
\hline \multicolumn{2}{|c|}{$\begin{array}{l}\text { When the carbon content is less than or equal to } 0.12 \% \text {, the carbon equivalent shall be calculated using the following } \\
\text { formula for } C E(P c m)\end{array}$} \\
\hline \multicolumn{2}{|c|}{$C E(P c m)=C+\frac{S i}{30}+\frac{M n}{30}+\frac{C u}{30}+\frac{N i}{30}+\frac{C r}{30}+\frac{M o}{30}+\frac{V}{30}+5 B$} \\
\hline \multicolumn{2}{|c|}{$\begin{array}{l}\text { f When the carbon content is greater than } 0.12 \% \text {, the carbon equivalent shall be calculated using the following formula for } \\
\mathrm{CE}(\mathrm{IIW})\end{array}$} \\
\hline$C E(I I W)=C+\frac{M n}{6}+\frac{(C r+M o+V)}{30}+\frac{(N i+C u)}{15}$ & \\
\hline
\end{tabular}


Before the chemical attack, the specimens were ground using sandpaper of 100-1000 mesh. Then, a polishing process was performed using diamond paste $(1 \mu \mathrm{m})$ as the abrasive material. Finally, the grinding and polishing residues were removed using water, ethanol, and drying.

Atomic force microscopy (AFM) was also used for steel plate characterization. Analyses were conducted using the Park Systems/XE70 microscope in non-contact mode and a cantilever with a force constant equal to $42 \mathrm{~N} / \mathrm{m}$.

\section{Surface cleaning and activation of API-5L X42-PSL2}

Prior to the deposition of FBE coatings, the steel samples were subjected to a specific surface treatment process. First, the specimens were cleaned by immersion in acetone for $10 \mathrm{~min}$, followed by immersion in ethanol for $15 \mathrm{~min}$, at room temperature, for mild degreasing and organic removal. Next, the chemical etching method with $\mathrm{HCl}$ solution $(0.58 \% \mathrm{v} / \mathrm{v})$ was used for removing any oxidized species on the steel surface. The pieces were immersed in an acid bath for $20 \mathrm{~min}$ at $57 \pm 3{ }^{\circ} \mathrm{C}$ under stirring. Finally, the steel surface was stabilized by immersion in hydrogen peroxide for $30 \mathrm{~min}$, and dried in oven at $57 \pm 3{ }^{\circ} \mathrm{C}$ for $4 \mathrm{~h}$.

\section{Functionalization of steel surface by organosilanes}

After cleaning, the samples were immersed in a sodium hydroxide solution $(5.75 \% \mathrm{w} / \mathrm{v})$ for $15 \mathrm{~min}$. This preparation aimed at producing uniform and hydroxyl-activated steel surfaces for the subsequent chemical functionalization with organosilanes. Next, the specimens were dried with acetone and, lastly, chemically modified using 3-GPTMS or 3-APTES, as follows.

a. The 3-GPTMS was added in an aqueous/alcohol solution (80 \% distilled water: $20 \%$ methanol, $\mathrm{pH}=5.0 \pm 0.2$ with acetic acid) to yield a $2 \%(\mathrm{v} / \mathrm{v})$ final concentration. The solution was allowed to hydrolyze for $48 \mathrm{~h}$ prior to use for the hydrolysis of alkoxide groups and silanol formation. Next, the specimens were immersed in this solution for $20 \mathrm{~s}$ and then cured at $150 \pm 5{ }^{\circ} \mathrm{C}$ for $1 \mathrm{~h}$ for covalent bonds formation (Additional file 1: Figure S1).

b. The 3-APTES was added in an aqueous/alcohol solution (90 \% distilled water: $10 \%$ methanol, natural $\mathrm{pH}$ ) to yield a $2 \%(\mathrm{v} / \mathrm{v})$ final concentration. The solution was allowed to hydrolyze for 30 min prior to use for the hydrolysis of alkoxide groups and silanol formation. Next, the specimens were immersed in this solution for $30 \mathrm{~s}$ and then cured at of $70 \pm 5{ }^{\circ} \mathrm{C}$ for $1.5 \mathrm{~h}$ for condensation reactions (Additional file 2: Figure S2).

Table 2 presents the main characteristics of organosilanes and the deposition conditions used.

The influence of surface functionalization on the hydrophilic/hydrophobic behavior of the steel surface was estimated via contact angle measurements carried out by depositing DI water droplets $(50 \mu \mathrm{L})$ on the steel surface. The apparatus used for measurements was a digital camera Canon Rebel T3 and image analysis software (ImageJ, version 1.44, public domain, National Institutes of Health). 
Table 2 Chemical functionalization process parameters using 3-GPTMS e 3-APTES on steel API 5L X42 substrate

\begin{tabular}{|c|c|c|}
\hline Organosilanes & 3-GPTMS & 3-APTES \\
\hline Chemical Formula & {$\left[\mathrm{OCH}_{2} \mathrm{CHCH}_{2} \mathrm{O}\left(\mathrm{CH}_{2}\right)_{3}\right] \mathrm{Si}\left(\mathrm{OCH}_{3}\right)_{3}$} & {$\left[\mathrm{NH}_{2}\left(\mathrm{CH}_{2}\right)_{3}\right] \mathrm{Si}\left(\mathrm{OCH}_{2} \mathrm{CH}_{3}\right)_{3}$} \\
\hline \multicolumn{3}{|l|}{ Chemical structure } \\
\hline \multirow[t]{3}{*}{ Organofunctional group } & $\mathrm{CH}_{2} \mathrm{OCHCH}_{2} \mathrm{O}-$ & $-\mathrm{NH}_{2}$ \\
\hline & & $\mathrm{H}_{2} \mathrm{~N}$ \\
\hline & Glycidoxy & Amino \\
\hline \multirow[t]{2}{*}{ Organosilane Solution } & $2 /(80 / 20) \vee /(v / v)$ & $2 /(90 / 10) v /(v / v)$ \\
\hline & $\begin{array}{l}\text { 3-GPTMS/(deionized water/methanol } \\
\text { solution) }\end{array}$ & $\begin{array}{l}\text { 3-APTES/(deionized water/ethanol } \\
\text { solution) }\end{array}$ \\
\hline Hydrolysis Time (h) & 48 & 0.5 \\
\hline $\mathrm{pH}$ & $5-5.5$ (acetic acid) & pH natural \\
\hline Molar ratio water/alkoxide & 480.5 & 452.5 \\
\hline Immersion time (s) & 20 & 30 \\
\hline Cure temperature $\left({ }^{\circ} \mathrm{C}\right)$ & $150 \pm 5$ & $70 \pm 5$ \\
\hline Cure Time (h) & 1 & 1.5 \\
\hline
\end{tabular}

Fourier transform infrared spectroscopy (FTIR) was used to characterize the presence of chemical groups at the surface of steel, in order to demonstrate the effectiveness of the developed procedure for functionalization. The attenuated total reflectance (ATR) mode was used (Nicolet 6700, Thermo Electron Corp.) within the range between 4000 and $675 \mathrm{~cm}^{-1}$. Each spectrum was recorded with a resolution of $4 \mathrm{~cm}^{-1}$ with a total of 32 scans. Further, to obtain image mapping of the chemical groups, Nicolet iN10 Infrared microscope (Thermo Scientific) with OMNIC Picta microscopy software (Thermo Scientific) was used to collect images from the aminosilane-modified steel surface. The motorized stage and the Slide-On MicroTip Ge ATR crystal accessory obtained spectra over an area of $400 \mu \mathrm{m} \times 400 \mu \mathrm{m}$ with $100 \mu \mathrm{m}$ steps (X and $\mathrm{Y}$ ) allowing area map collection $\left(4000-675 \mathrm{~cm}^{-1}, 16\right.$ scans, $8 \mathrm{~cm}^{-1}$ resolution).

\section{FBE coating}

Characterization of FBE powder and coating The moisture content was determined gravimetrically after drying the sample powder at $110 \pm 5{ }^{\circ} \mathrm{C}$ for $12 \mathrm{~h}$. The material obtained (solids content) was calcined in an oven at $610 \pm 5{ }^{\circ} \mathrm{C}$ for $2 \mathrm{~h}$ and the residue of calcination was associated with the filler present in the material. The resin content was obtained by calculating the difference between the solid content $(100 \%)$ and the filler content. The results were expressed as the percentage (\% mass) of material obtained in each step of the assay.

Thermogravimetric (TGA) and differential scanning calorimetry (DSC) analyses were performed using SDT Q-600 simultaneous TGA/DSC instrument (TA Instruments, 
New Castle, DE, USA). Samples were used for the experiments at temperatures of up to $600{ }^{\circ} \mathrm{C}$ with a heating rate of $10{ }^{\circ} \mathrm{C} \mathrm{min}^{-1}$. The samples were loaded into an open platinum crucible. The TGA and DSC curves were recorded simultaneously with $0.1 \mu \mathrm{g}$ sensitivity. The analysis was performed under continuous flow of dry nitrogen gas $\left(50 \mathrm{~mL} \mathrm{~min}^{-1}\right)$.

The morphology of the FBE powder and FBE coating was evaluated using scanning electron microscopy (SEM, FEI-INSPECTTM S50) coupled with energy dispersion X-ray spectroscopy (EDX, EDAX GENESIS). Before examination, the samples were coated with a thin carbon film by sputtering under a low deposition rate, substrate cooling, and maximum distance between the target and sample in order to avoid sample damage. Images of secondary electrons (SE) were obtained with an accelerating voltage of $15 \mathrm{kV}$. The FBE particle size and size distribution data were obtained based on the SEM images by measuring at least 200 randomly selected nanoparticles using an image processing program (ImageJ, version 1.44, public domain, National Institutes of Health).

The crystalline phases present in the FBE powder were characterized by X-ray diffraction (XRD) patterns recorded using a PANalytical Empyream diffractometer $(\mathrm{Cu}-\mathrm{K} \alpha$ radiation with $\lambda=1.5406 \AA$ ). Measurements were performed in the $2 \theta$ range of $15^{\circ}-75^{\circ}$ with steps of $0.06^{\circ}$.

The FBE powder was also analyzed by the diffuse reflectance infrared Fourier transform spectroscopy (DRIFTS) method (Nicolet 6700, Thermo Fischer) over the range of $4000-400 \mathrm{~cm}^{-1}$ using 64 scans and a $2 \mathrm{~cm}^{-1}$ resolution with subtraction of the $\mathrm{KBr}$ background. The powder samples were mixed in a ratio of $1 \%$ (wt\%) to $\mathrm{KBr}$ powder dried at $110 \pm 5^{\circ} \mathrm{C}$ for $2 \mathrm{~h}$.

The FBE coatings were evaluated in the range of medium and near infrared (NIR) wavelengths using attenuated total reflectance (ATR, 4000-675 $\mathrm{cm}^{-1}, 32$ scans, and a $4 \mathrm{~cm}^{-1}$ resolution) and NIR integrating sphere $\left(7400-4000 \mathrm{~cm}^{-1}, 16\right.$ scans and a $8 \mathrm{~cm}^{-1}$ resolution), respectively, with background subtraction.

Deposition and cure of FBE on API 5L X42 steel surface FBE powder was deposited on the steel substrate and spread with a mold to guarantee homogeneous thickness. In the sequence, the system was heated at $248 \pm 5{ }^{\circ} \mathrm{C}$ for $5 \mathrm{~min}$ and cooled down to $25^{\circ} \mathrm{C}$ at room temperature, as schematically represented in Additional file 3: Figure S3.

The coating was applied on the clean steel surface (bare steel) and on the chemically modified steel surface using 3-GPTMS or 3-APTES.

Adhesion tests according to ASTM D3359-09 [16] and ASTM D4541-09 [17] were carried out to measure the adherence in the FBE/steel interface after cleaning and after chemical modification with silanes. The ASTM D3359-09 test used $3 \mathrm{M}^{\circledR}$ adhesive tape Scotch $^{\circledR}$ 8809, an adhesive-based resin and rubber. For the ASTM D4541-09 test, the portable PosiTest brand (AT-M Manual Adhesion Tester) was used, with detection limit of $23.36 \pm 0.01 \mathrm{MPa}$.

\section{Results and discussion}

\section{Characterization of steel substrate}

The chemical composition (according to ASTM A751 [18]) and mechanical properties (according to ASTM A370 [19]) of the steel plate used in this study are summarized in 
Table 3. The results indicated that the AP1 5L standard specifications listed in Table 1 were fully complied.

The microphotographs of API 5L X42 carbon steel under OM (200X) and SEM (1500X) are shown in Fig. 1a, b, revealing a ferrite-perlite microstructure. The white regions in the OM results are associated with perlite, which is hard and brittle, and the dark areas are the soft and ductile ferrite [20]. This ferrite-perlite microstructure is in agreement with the low carbon content of the sample, as determined by chemical analysis $(0.13 \mathrm{wt} \%$, Table 3$)$ [21]. The ferrite grain size was obtained by OM following the

Table 3 Chemical composition [18] and mechanical properties [16] of API 5 L X42 steel sample used in this study

\begin{tabular}{|c|c|c|c|c|c|c|c|c|c|c|c|}
\hline \multicolumn{12}{|c|}{ Chemical composition $^{\mathrm{a}}$} \\
\hline Element & C & $\mathrm{Si}$ & $\mathrm{Mn}$ & P & S & Al & $\mathrm{Cu}$ & $\mathrm{Nb}$ & V & $\mathrm{Ti}$ & $\mathrm{Cr}$ \\
\hline$\% w t$ & 0.13 & 0.18 & 1.02 & 0.015 & 0.002 & 0.029 & 0.01 & 0.002 & 0.001 & 0.001 & 0.02 \\
\hline Element & $\mathrm{Ni}$ & Mo & Sn & N & B & $\mathrm{Ca}$ & $\mathrm{Sb}$ & $\mathrm{Pb}$ & CE (IIW) & CE (Pcm) & Fe \\
\hline$\% w t$ & 0.02 & 0.00 & 0.001 & 0.0041 & 0.0001 & 0.0012 & 0.00 & 0.002 & 0.31 & 0.19 & balance \\
\hline \multicolumn{12}{|c|}{ Mechanical properties (MPa) } \\
\hline \multicolumn{5}{|c|}{ Yield Strength } & \multicolumn{7}{|l|}{344} \\
\hline \multicolumn{5}{|c|}{ Ultimate Tensile Strength } & 472 & & & & & & \\
\hline
\end{tabular}

${ }^{a}$ Fe balance
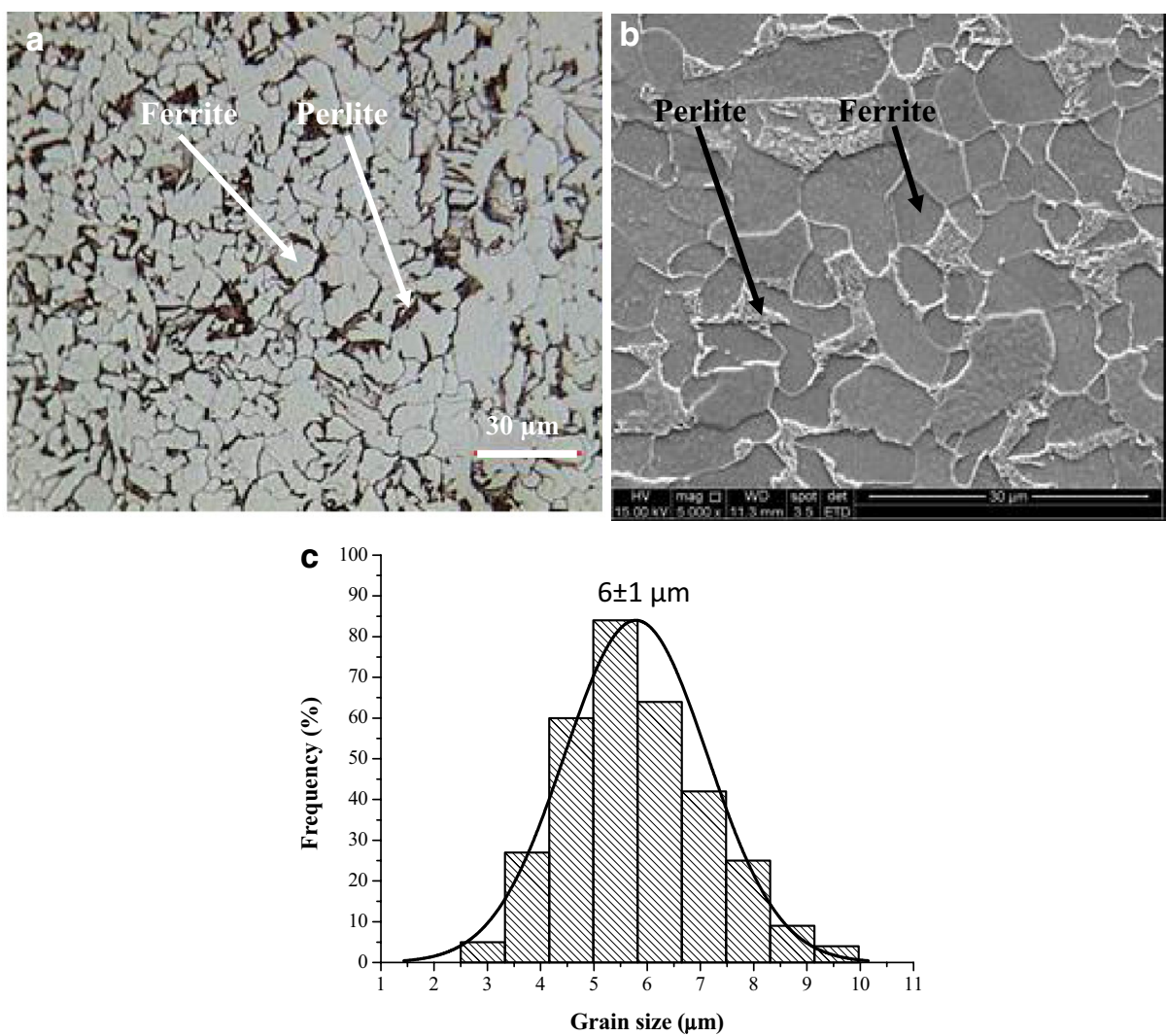

Fig. 1 Microphotographs of API 5L X42 carbon steel after etching with Nital $2 \%$ a Optical microscopy $(\times 200)$, and b scanning electron microscopy (secondary electrons, SE, $\times 1500$ ). c Ferrite grain size distribution 
procedures of the standard ASTM E112-13-Standard Test Methods for Determining Average Grain Size. The histogram of size distribution is shown in Fig. 1c, revealing an average grain size of $6 \pm 1 \mu \mathrm{m}$, which corresponds to an equivalent, G, ASTM grain size number of 11 . This is characteristic of a very fine grain size that improves the strength of the material [21, 22]. However, there is no direct relationship between the grain size and API 5L grade steels with the mechanical properties of a steel as they depend on several aspects such as fabrication route, grain size, and presence of inclusions [22].

\section{Characterization of steel substrate after cleaning (bare steel)}

The steel surface was cleaned for removal of organic materials and rust by immersion in acetone and ethanol, followed by acid etching using hydrochloric acid. According to Tang et al. [23], the reactions involved in the acid pickling process are shown in Eqs. (1)(4) and indicate the oxidized layer removal Eqs. (1-3) and dissolution of base metal Eq. (4).

$$
\begin{aligned}
& \mathrm{Fe}_{3} \mathrm{O}_{4(\mathrm{~s})}+8 \mathrm{H}_{(\mathrm{l})}^{+} \rightarrow 2 \mathrm{Fe}_{(\mathrm{l})}^{3+}+\mathrm{Fe}_{2}^{+(\mathrm{l})}+4 \mathrm{H}_{2} \mathrm{O}_{(\mathrm{l})} \\
& \mathrm{Fe}_{2} \mathrm{O}_{3(\mathrm{~s})}+6 \mathrm{H}_{(\mathrm{l})}^{+} \rightarrow 2 \mathrm{Fe}_{(\mathrm{l})}^{3+}+3 \mathrm{H}_{2} \mathrm{O}_{(\mathrm{l})} \\
& \mathrm{FeO}(\mathrm{s})+2 \mathrm{H}_{(\mathrm{l})}^{+} \rightarrow \mathrm{Fe}_{(\mathrm{l})}^{2+}+\mathrm{H}_{2} \mathrm{O}_{(\mathrm{l})} \\
& \mathrm{Fe}_{(\mathrm{s})}+2 \mathrm{H}_{(\mathrm{l})}^{+} \rightarrow \mathrm{Fe}_{(\mathrm{l})}^{2+}+\mathrm{H}_{2(\mathrm{~g})}
\end{aligned}
$$

In the sequence, the base metal was immersed in hydrogen peroxide for surface stabilization following Eqs. (5)-(7) [24-26].

$$
\begin{aligned}
& \mathrm{H}_{2} \mathrm{O}_{2(\mathrm{aq})} \rightarrow \mathrm{H}_{2} \mathrm{O}_{(\mathrm{aq})}+1 / 2 \mathrm{O}_{2(\mathrm{~g})} \\
& 2 \mathrm{Fe}_{(\mathrm{s})}+2 \mathrm{H}_{2} \mathrm{O}_{(\mathrm{aq})}+\mathrm{O}_{2(\mathrm{~g})} \rightarrow 2 \mathrm{Fe}(\mathrm{OH})_{2(\mathrm{~s})} \\
& 2 \mathrm{Fe}(\mathrm{OH})_{2(\mathrm{~s})}+3 \mathrm{H}_{2} \mathrm{O}_{(\mathrm{aq})}+1 / 2 \mathrm{O}_{2(\mathrm{~g})} \rightarrow 2 \gamma-\mathrm{FeOOH}_{(\mathrm{s})}+4 \mathrm{H}_{2} \mathrm{O}_{(\mathrm{aq})}
\end{aligned}
$$

A comparison between Fig. 2a, c clearly reveals the removal of the loose and brittle oxidized layers upon acid pickling and hydrogen peroxide treatments. EDX spectra (Fig. 2b, d) also indicate the reduction of oxygen band in the cleaned sample, associated with the dissolution of iron oxides. In addition, the cleaning process also increased the roughness of the steel surface that is crucial for the adhesion of the coating layers. AFM images (Fig. 2e) also reveal the roughness of the surface with an increase in the root mean square (RMS) parameter $\left(R_{\mathrm{q}}\right)$ from $0.6 \pm 0.3$ to $1.9 \pm 0.3 \mu \mathrm{m}$ after cleaning.

Because metallic materials do not absorb infrared radiation, the FTIR spectrum of cleaned steel (not shown) can only reveal the presence of the metal hydroxides and oxyhydroxides that are expected to be formed after the treatment with hydrogen peroxide.

\section{Characterization of functionalized steel substrate}

The contact angle is a relatively simple parameter for investigating the properties of surfaces after chemical modifications. Figure 3 shows the dependence of the contact angle 


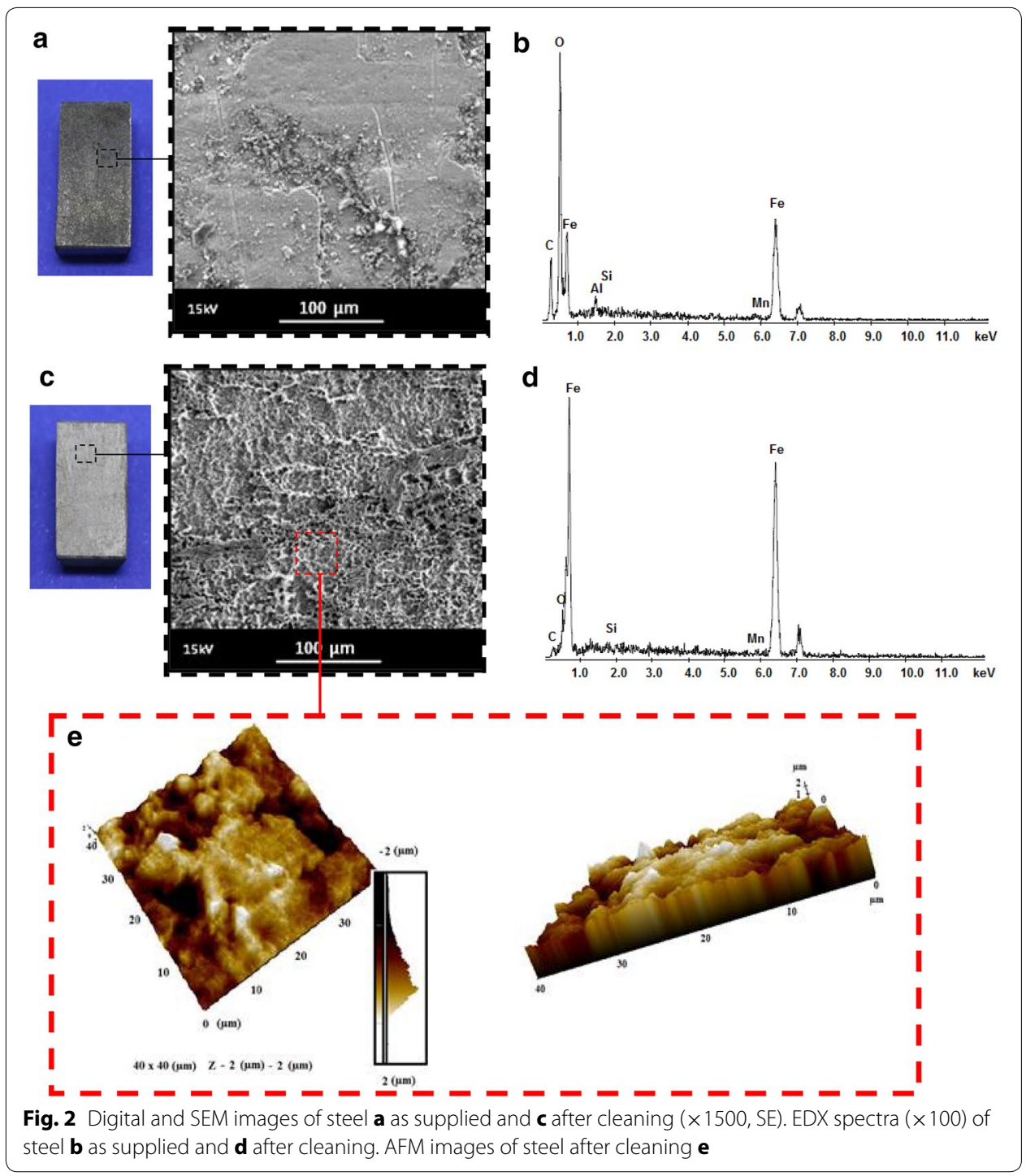

with the presence of organosilane modifier owing to the introduction of hydrophilic/ hydrophobic species. The contact angles measured from DI water droplets deposited on bare steel and hydroxyl-activated steel surfaces were lower than $10^{\circ}$. These indicate higher wettability of these solid supports when compared with the 3-APTES and 3-GPTMS-modified surfaces that presented contact angles of $69 \pm 3^{\circ}$ and $57 \pm 4^{\circ}$, respectively. The measured values are in agreement with published reports on alkylsilanes as modifiers $[27,28]$, and they can be explained based on the hydrophobic characteristic of propyl spacer of 3-APTES and 3-GPTMS organosilanes. In addition, the slightly higher hydrophilic behavior observed for 3-GPTMS-modified steel may be associated to the number of hydrogen bonds that could be established between the water droplet and the organofunctional group, as shown in Fig. 3. Since the number of sites for hydrogen bond is estimated of 4 per molecule for glycidoxy and 3 per molecule for amine organofunctional groups, the liquid water spreads over the 3-GPTMS-modified surface to a larger extent. 


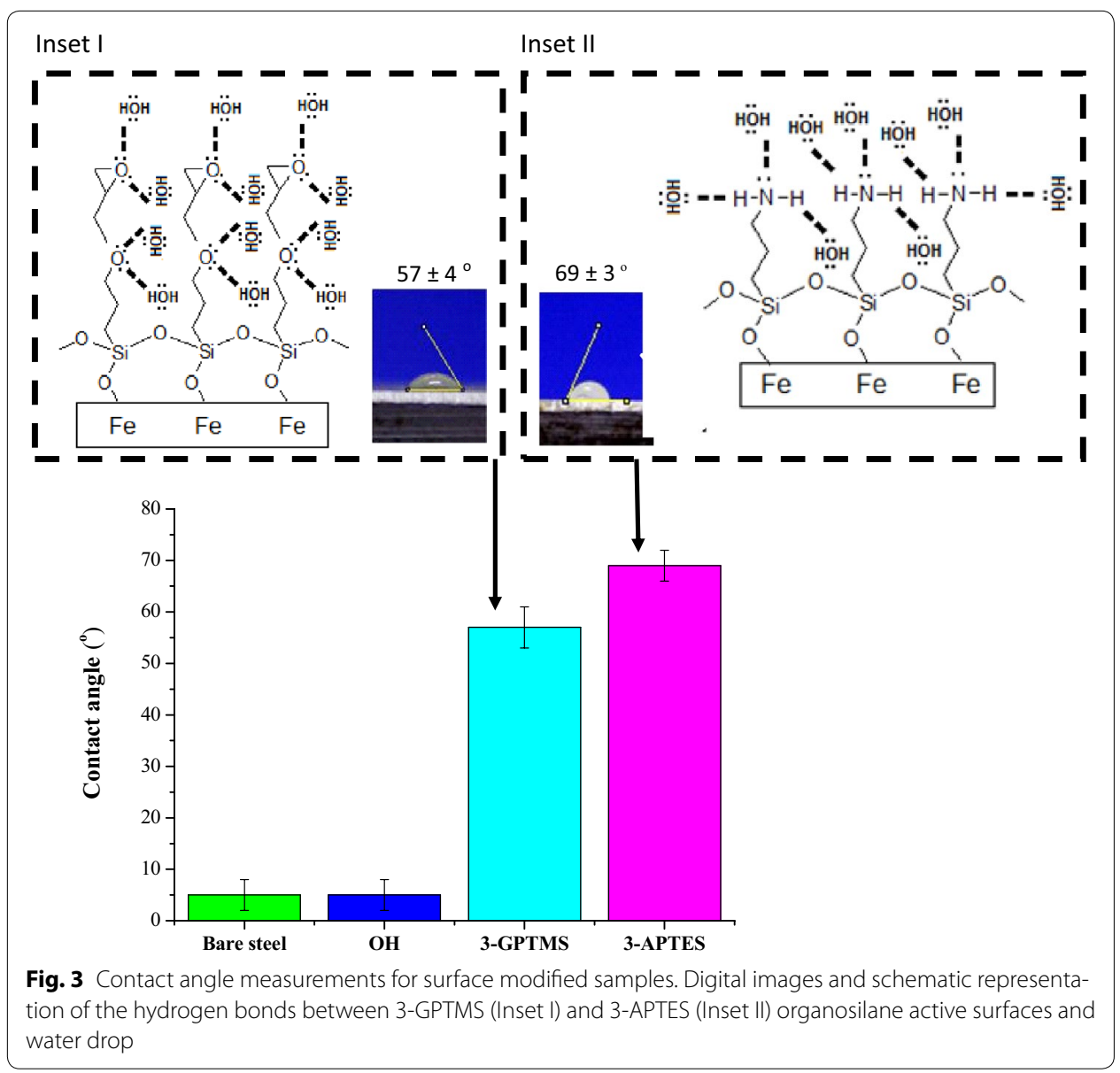

FTIR spectroscopy was used to identify the occurrence of surface modification by organosilanes. For 3-APTES (Fig. 4a) and 3-GPTMS (Fig. 4b), antisymmetric $\left(v_{\mathrm{as}}\right)$ and symmetric $\left(v_{\mathrm{s}}\right)-\mathrm{CH}_{2}$ stretching vibration bands are observed at 2940-2920 and 2890$2860 \mathrm{~cm}^{-1}$ [27], respectively, related to the propyl spacer group of organosilane. The other vibration band that is typical of both silanes is attributed to the asymmetric $\mathrm{Si}-\mathrm{O}-$ $\mathrm{Si}$ and $\mathrm{Si}-\mathrm{O}-$ metal $(\mathrm{M})$ stretching in the $980-1200 \mathrm{~cm}^{-1}$ range. Siloxane bonds (Si-O$\mathrm{Si}$ ) are formed from the condensation of the silanol groups, and $\mathrm{Si}-\mathrm{O}-\mathrm{M}$ vibrations result from the covalent bonds between silanol groups and metal hydroxyl groups on the surface of steel. In addition, the bands within $3600-3200$ and $975-865 \mathrm{~cm}^{-1}$ may be assigned to the stretching and bending vibrations of $\mathrm{Si}-\mathrm{OH}$, respectively, owing to the incomplete condensation of silanol formed during hydrolysis [13, 27, 29]. This absence of complete condensation of silanol groups is considered favorable for later adhesion of fusion bonded epoxy resins once it increases and facilitates the penetration of the polymeric resin at the interphase between the metal substrate and the organic polymer [13, 29].

Moreover, characteristic peaks from organofunctional groups of silanes were also detected. In the amino-modified steel substrate (Fig. 4a), a broad band from 3500 to $3200 \mathrm{~cm}^{-1}$ is attributed to $v_{\mathrm{s}}$ absorptions from $\mathrm{N}-\mathrm{H}$ overlapped with $\mathrm{Si}-\mathrm{OH}$ groups, and 


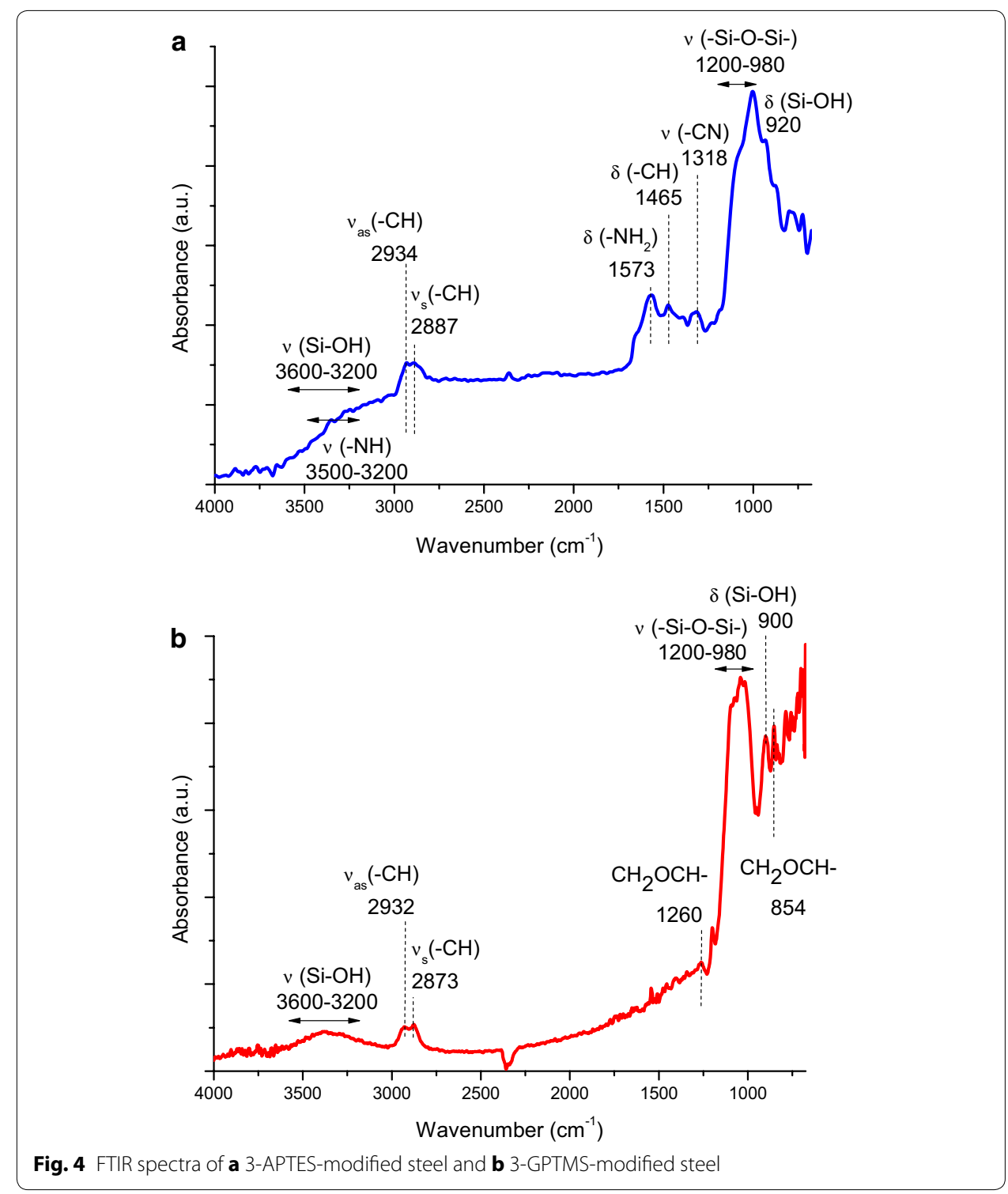

the bands at 1573 and $1318 \mathrm{~cm}^{-1}$ are associated with the in-plane scissoring bending of primary amines $\left(-\mathrm{NH}_{2}\right)$ and the stretching of $\mathrm{C}-\mathrm{N}$ bonds, respectively [27]. The FTIR analysis of glycidoxy-modified support (Fig. 4b) also presented peaks from $\mathrm{CH}_{2} \mathrm{OCH}-$ bonds at 1260 and $854 \mathrm{~cm}^{-1}$ characteristic of the organofunctional group [30]. The detection of these organofunctional groups at the surface indicate that they are available for creation of covalent bonds with the epoxy coating, favoring the adhesion behavior [13].

To assess qualitatively the distribution of the silane modifier on the surface of the steel samples, FTIR microscopy was also performed on randomly selected areas. The image mappings associated with $-\mathrm{NH}_{2}, \mathrm{Si}-\mathrm{O}-\mathrm{Si}$ and $-\mathrm{CH}_{2}$ bands presented in Fig. 5 indicate that the silane adhesion primer is distributed throughout the steel substrate despite the differences in absorbance, once the ATR technique is not directly quantitative. Regarding to the thickness of the silane-based films, it is considered that thin multilayers were 


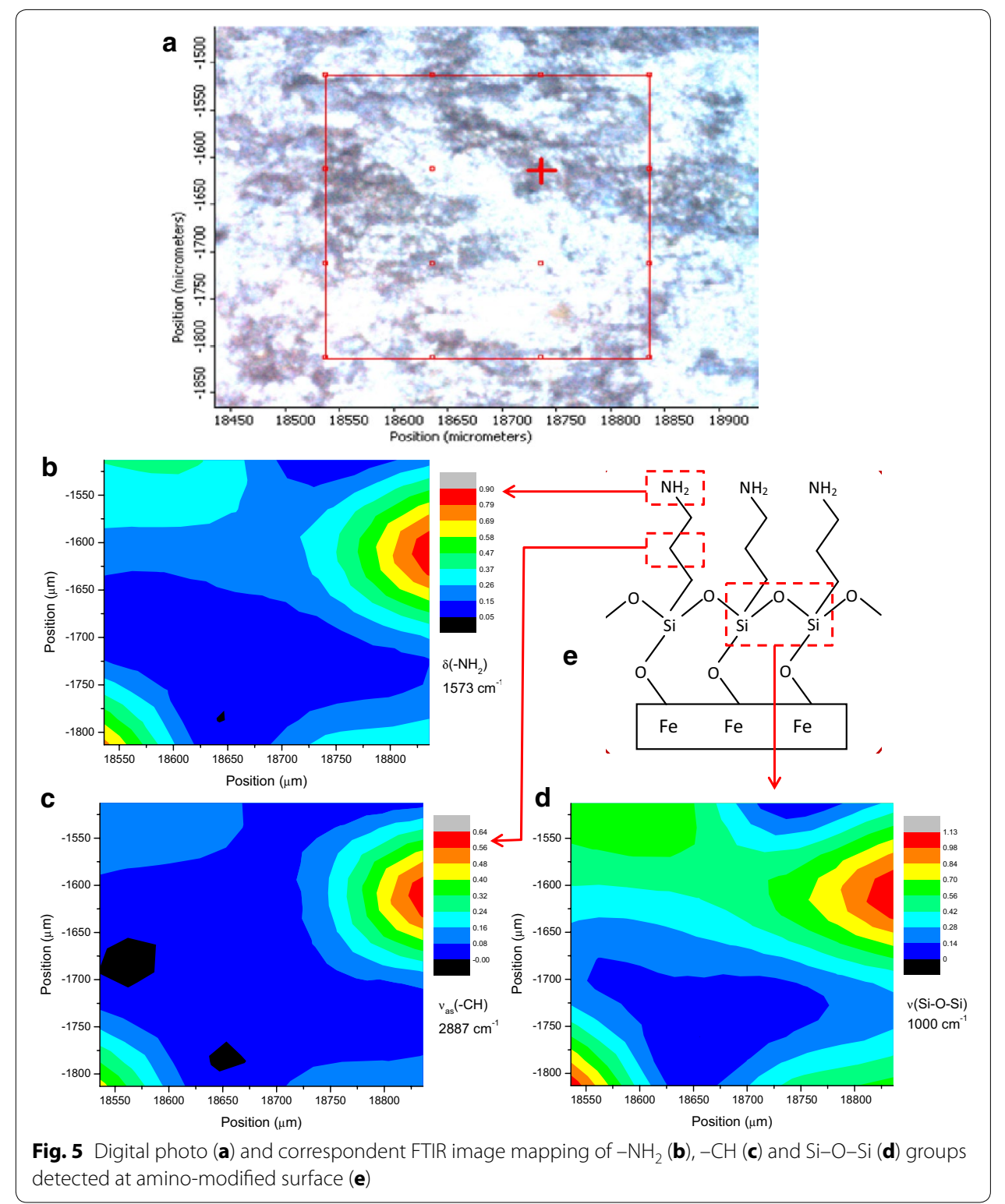

formed due to thermodynamics and kinetics conditions used during the functionalization of the steel surfaces $[13,14,31]$. Therefore, the procedure for chemically modifying the steel surface properties can be considered effective.

\section{Characterization of FBE}

Thermal treatment of the as-supplied FBE powder at $110 \pm 5{ }^{\circ} \mathrm{C}$ indicated a moisture content of $0.5 \pm 0.1 \%$. After calcination at $610 \pm 5{ }^{\circ} \mathrm{C}$, the weight percentage of resin and inorganic content were calculated as $66.7 \pm 3.0$ and $32.8 \pm 3.0 \mathrm{wt} \%$, respectively. These results are in agreement with the manufacturer specifications that indicate moisture content lower than $6 \mathrm{wt} \%$, inorganic content in the range of $21-43 \mathrm{wt} \%$, and resin content from 52 to $76 \mathrm{wt} \%$. 
SEM images of FBE (Fig. 6a) revealed that the powder comprises particles of several sizes ranging from 5 to $150 \mu \mathrm{m}$, most within 5-20 $\mu \mathrm{m}$. The backscattered electron images (Fig. 6a, b) shown that the powder is a composite material with inorganic particles (bright) immersed in the polymeric matrix (dark). SEM image of the inorganic filler obtained after resin calcination (Fig. 6c) indicated that the inorganic particles had different sizes and shapes (aspect ratio). The EDX spectra (Additional file 4: Figure S4) show that the smallest $(<0.5 \mu \mathrm{m})$ and rounded particles are rich in Ti and the acicular particles are calcium silicate. The XRD pattern of this inorganic filler (Fig. 6d) showed that the Ti-rich phase was compatible with anatase $\left(\mathrm{TiO}_{2}\right.$, ICCD, International Centre for Diffraction Data, 84-1286) and that the calcium silicate was wollastonite $\left(\mathrm{CaSiO}_{3}, \mathrm{ICCD}\right.$ 84-0654). Wollastonite is needle-shaped, and SEM images showed that different grades of aspect ratio (low, medium and high) were present in the material. It is considered functional filler once its acicular particles increase the flexural modulus and lower the thermal expansion and shrinkage, and its fine particle size offers excellent impact resistance. In addition, the relatively high hardness of wollastonite promotes effective scratch and wear-resistance to the composite coating [32].

FBE resins are usually based on poly(bisphenol A-co-epichlorohydrin) end-capped glycidyl (DGEBA, Fig. 7a) and dicyandiamide (DDA, Fig. 7b) as the curing agent. The FTIR spectrum obtained from FBE powder (Fig. 7c) indicated that the epoxy composite
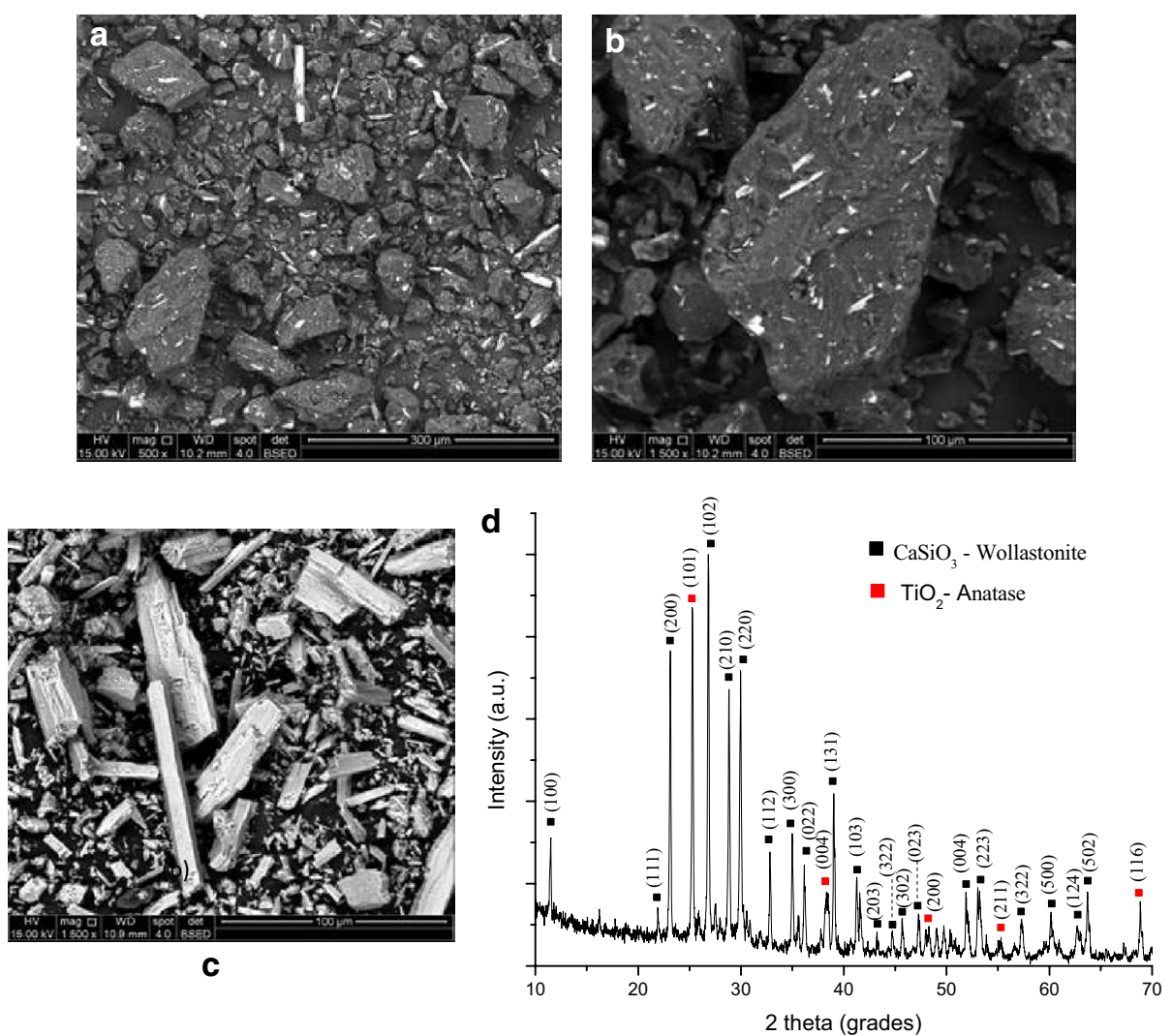

Fig. 6 SEM image of FBE powder at $\mathbf{a} \times 500$ and $\mathbf{b} \times 1500$ (backscattered electrons, BSE). c SEM image (SE, $\times 1500$ ) and $\mathbf{d}$ XRD pattern of FBE filler 


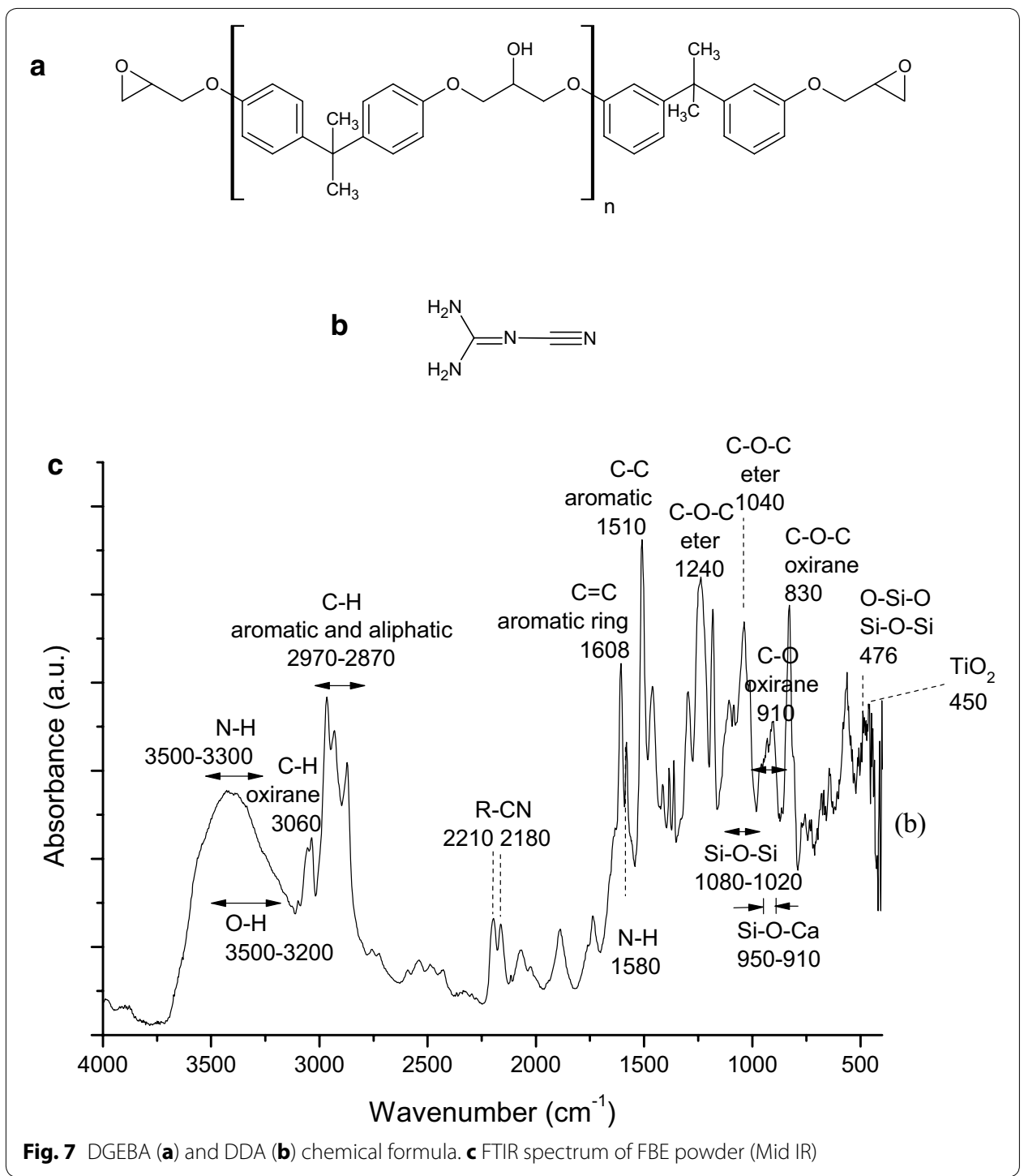

under evaluation presented vibrational bands characteristic of these organic components overlapped with the bands associated with inorganic filler. Table 4 summarizes the main vibrational bands observed in the FBE under evaluation [33-36].

However, as FBE is a thermosetting polymer that cures upon heating, DSC curves can provide information on glass transition temperature $(\mathrm{Tg})$, onset and completion of cure, and enthalpy of cure as the heat flows with increasing sample temperature. The DSC curve of FBE powder is shown in Fig. 8a. The first event that could be seen in Fig. 8a is an endothermic stepwise event associated with the Tg of FBE powder, indicating that at $62{ }^{\circ} \mathrm{C}$, the solid transformed to a viscous material. The second event observed was an exothermic peak related to curing reactions in the range of 140 and $240{ }^{\circ} \mathrm{C}$ and heat of cure of $47 \mathrm{~J} \mathrm{~g}^{-1}$. It is interesting to note that there was no volatile emission in the TGA curve (Fig. 8c) after the removal of adsorbed water $\left(\mathrm{T}<110{ }^{\circ} \mathrm{C}\right.$, mass loss $0.3 \pm 0.1 \%$ ), because FBE products usually contain no volatile organic compounds (zero-VOC). The third thermal event detected was the thermal degradation of the polymer, which agrees 
Table 4 FTIR vibrational bands of FBE components [33-36]

\begin{tabular}{|c|c|c|}
\hline Component & Wavenumber $\left(\mathrm{cm}^{-1}\right)$ & Band assignment \\
\hline \multirow[t]{8}{*}{ DGEBA } & $3500-3200$ & $\vee(\mathrm{O}-\mathrm{H})$ \\
\hline & 3060 & $\mathrm{v}(\mathrm{C}-\mathrm{H})$ of the oxirane ring \\
\hline & $2970-2870$ & $\mathrm{v}(\mathrm{C}-\mathrm{H})$ of $\mathrm{CH}_{2}$ and $\mathrm{CH}$ aromatic and aliphatic \\
\hline & 1608 & $\mathrm{v}(\mathrm{C}=\mathrm{C})$ of aromatic rings \\
\hline & 1506 & $v(C-C)$ of aromatic \\
\hline & 1040 & $\mathrm{v}(\mathrm{C}-\mathrm{O}-\mathrm{C})$ of ethers \\
\hline & 910 & $v(C-O)$ of oxirane group \\
\hline & 830 & $\mathrm{v}(\mathrm{C}-\mathrm{O}-\mathrm{C})$ of oxirane group \\
\hline \multirow[t]{4}{*}{ DDA } & $3500-3300$ & $v(\mathrm{~N}-\mathrm{H})$ \\
\hline & 2210 & $\mathrm{R}-\mathrm{CN}$ \\
\hline & 2180 & $\mathrm{R}-\mathrm{CN}$ \\
\hline & $1650-1500$ & $\delta(\mathrm{N}-\mathrm{H})$ of primary amines \\
\hline \multirow[t]{3}{*}{ Wollastonite } & $1080-1020$ & $v(\mathrm{Si}-\mathrm{O}-\mathrm{Si})$ \\
\hline & $950-910$ & $v(\mathrm{Si}-\mathrm{O}-\mathrm{Ca})$ \\
\hline & 476 & $\delta(\mathrm{Si}-\mathrm{O}-\mathrm{Si})$ and $\delta(\mathrm{O}-\mathrm{Si}-\mathrm{O})$ \\
\hline $\mathrm{TiO}_{2}$ anatase & 450 & $\mathrm{Ti}-\mathrm{O}$ \\
\hline
\end{tabular}

with the loss mass identified in the TGA curve (Fig. 8c). The FBE powder underwent thermal degradation beginning at about $320{ }^{\circ} \mathrm{C}$ with a mass loss of about $60 \%$ under purge gas. To verify the $\mathrm{Tg}$ of the cured polymer and the degree of cure, another experiment was carried out with the following thermal profile: 1 st step-temperature increase at $10^{\circ} \mathrm{C} \mathrm{min}-1$ up to $245^{\circ} \mathrm{C}$; 2nd step-isothermal curing at $245^{\circ} \mathrm{C}$ for $10 \mathrm{~min}$; 3rd stepcooling down to room temperature; 4th step-temperature increase at $10{ }^{\circ} \mathrm{C} \mathrm{min}-1$ up to $245{ }^{\circ} \mathrm{C}$. Based on the DSC curves (Fig. 8b), the Tg of the cured polymer at $245^{\circ} \mathrm{C}$ for 10 min increased to $87^{\circ} \mathrm{C}$ owing to the increase in the molecular weight of the resin system as a consequence of crosslinking reactions. In addition, there was no endothermic event in the range of $140-240{ }^{\circ} \mathrm{C}$ indicating that the resin was fully cured after the thermal treatment. Based on these experiments, the cure temperature information was obtained, and some samples were prepared for evaluating curing reactions using nearinfrared spectroscopy since the changes upon heating are not easily detected using midinfrared spectroscopy due to overlapping and low intensities of vibrational bands [33].

Figure 9 presents NIR-FTIR spectra of the FBE increasing the temperature and time of the curing process. Despite the complex mechanisms and reactions involved in the curing process of DGEBA resin [33, 34, 37], there is a general agreement about the main crosslinking reactions occurring in the matrix. At low temperatures practically no curing reaction occurs in an epoxy resin based in DGEBA and the cure agent dicyandiamide. Upon increasing the temperature, the curing process starts with the diffusion of the dicyandiamide into the epoxy resin and the reaction between the oxirane rings of DGEBA and primary and secondary amine groups of the dicyandiamide forming hydroxyl groups takes place $[33,37]$. As the reaction proceeds, the formed hydroxyl groups can react with cyano and oxirane groups leading to the formation of a highly crosslinked network through pathways that have not been completely elucidated yet and depend on the curing conditions [37]. As predicted by the reactions described above, the intensities of the vibrations associated with the epoxy groups at $4528 \mathrm{~cm}^{-1}\left(v\left(\mathrm{CH}_{2}\right)\right.$ and 


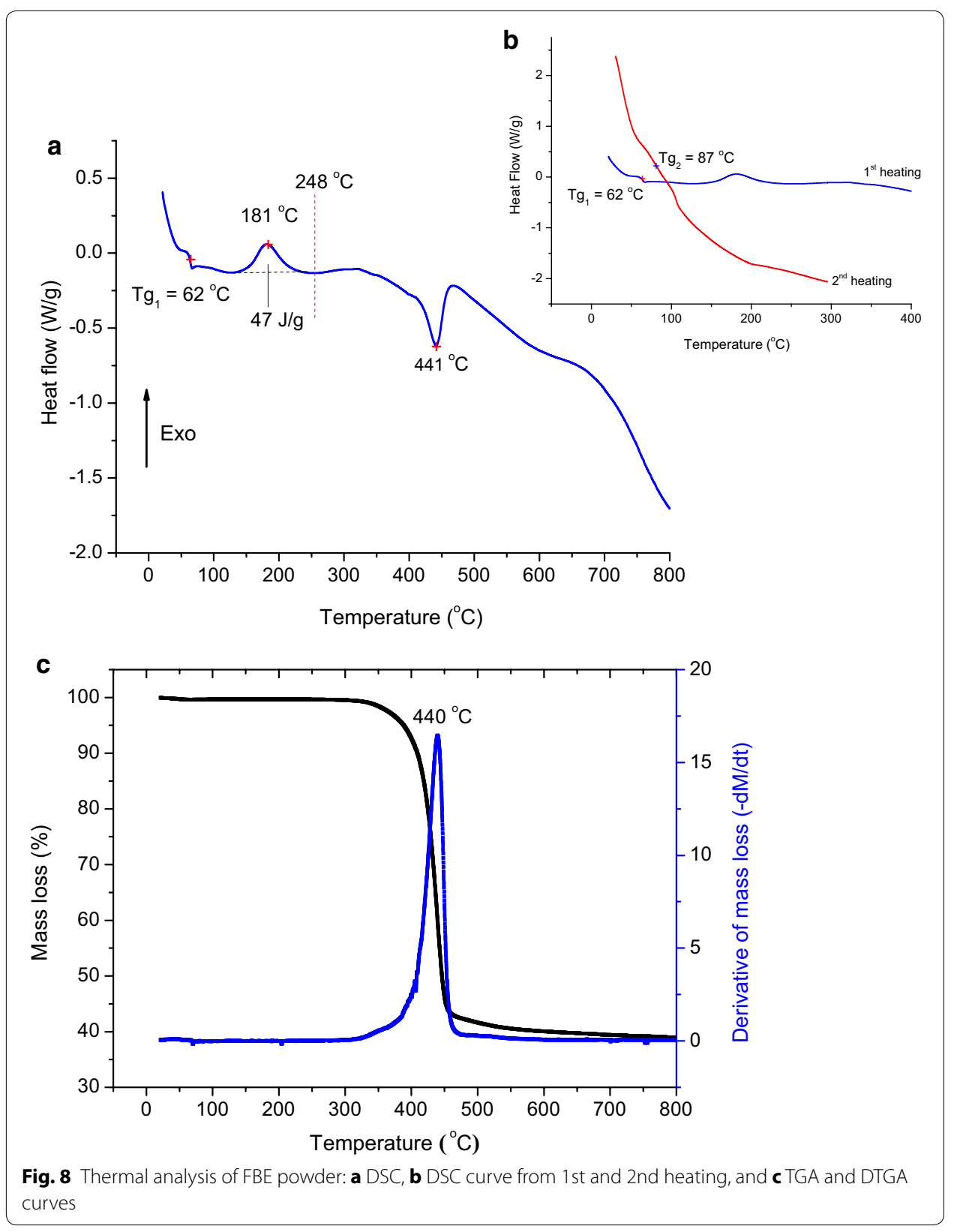

$\delta\left(\mathrm{CH}_{2}\right)$, Fig. 9-Detail II), $6069 \mathrm{~cm}^{-1}\left(v\left(\mathrm{CH}_{2}\right)\right.$ overtone, Fig. 9-Detail I), and $5885 \mathrm{~cm}^{-1}$ $\left(\mathrm{CH}\right.$ and $\mathrm{CH}_{2}$ combination, Fig. 9-Detail I) decreased with time of reaction and by raising in the temperature. The same trend was observed in the bands associated with primary and secondary amines at approximately $5050 \mathrm{~cm}^{-1}\left(\mathrm{NH}_{2}\right.$ stretching and bending combination, Fig. 9-Detail IV) and in the range of 6900-6450 $\mathrm{cm}^{-1}$ (symmetric and antisymmetric stretching first overtone of primary amines and a single band of secondary amines, Fig. 9-Detail III) once the oxirane ring is broken when reacting with amine groups [33, 38]. In addition, the band assigned to hydroxyls at $6985 \mathrm{~cm}^{-1}(v(\mathrm{OH})$ overtone, Fig. 9-Detail III) increased initially as a consequence of the epoxy ring opening followed by its reduction at longer reaction times after reacting with oxirane and cyano groups [33, 37, 38]. 


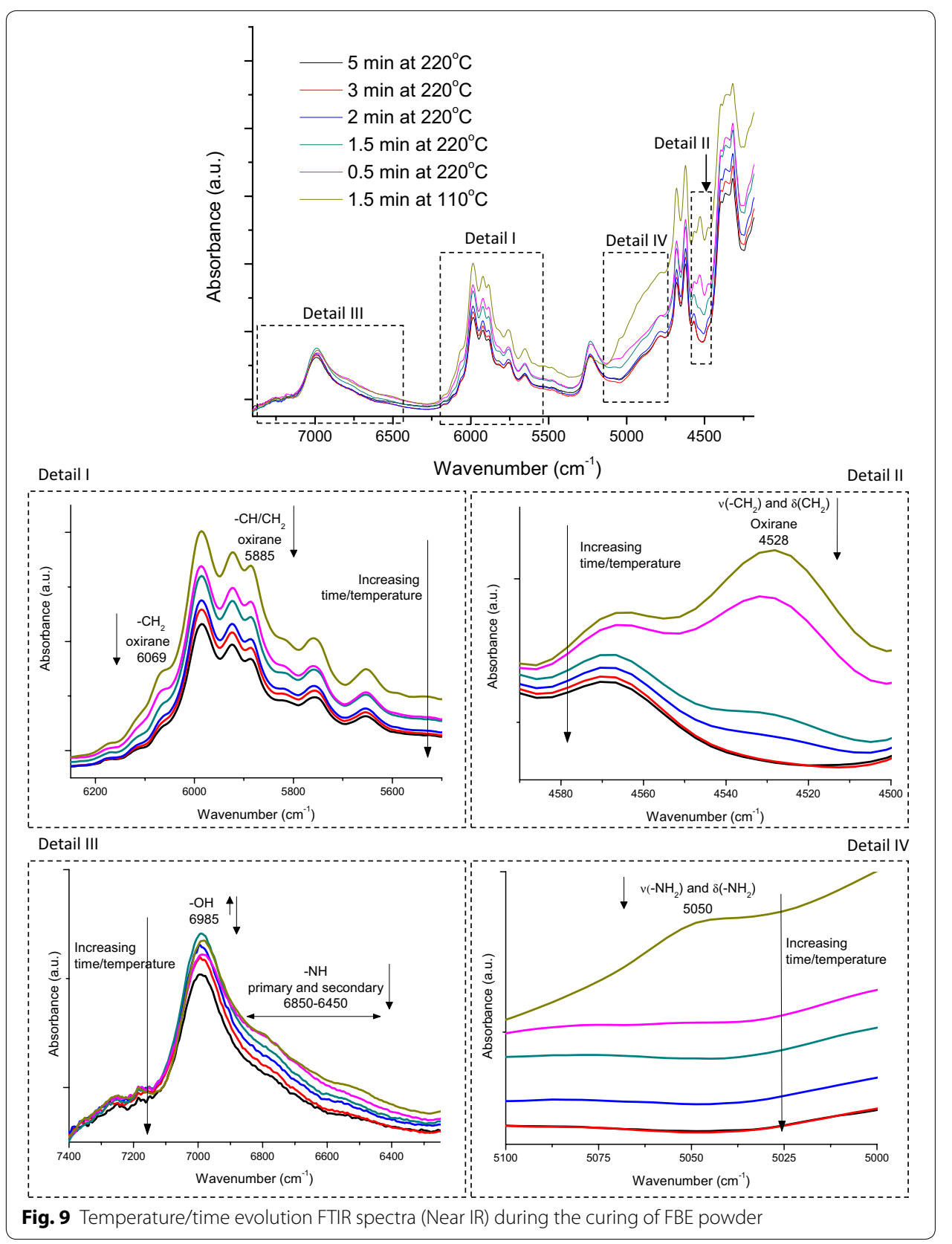

\section{Adhesion tests}

Based on DSC experiments, the samples were prepared for adhesion tests, as described in previous section (Experimental Procedure, 2.2.4.2). SEM images of the interface formed by the cured FBE and cleaned steel substrate are shown in Fig. 10. Upon heating and curing, viscous FBE flowed onto the solid support, and particles boundaries disappeared. A continuous polymeric matrix was formed with inorganic filler as the reinforcing material. No bubbles and interfacial flaws were detected. In addition, the thickness of the epoxy composite was $308 \pm 3 \mu \mathrm{m}$, in agreement with the specifications of CSA Standard $(250-350 \mu \mathrm{m})$ [39]. 


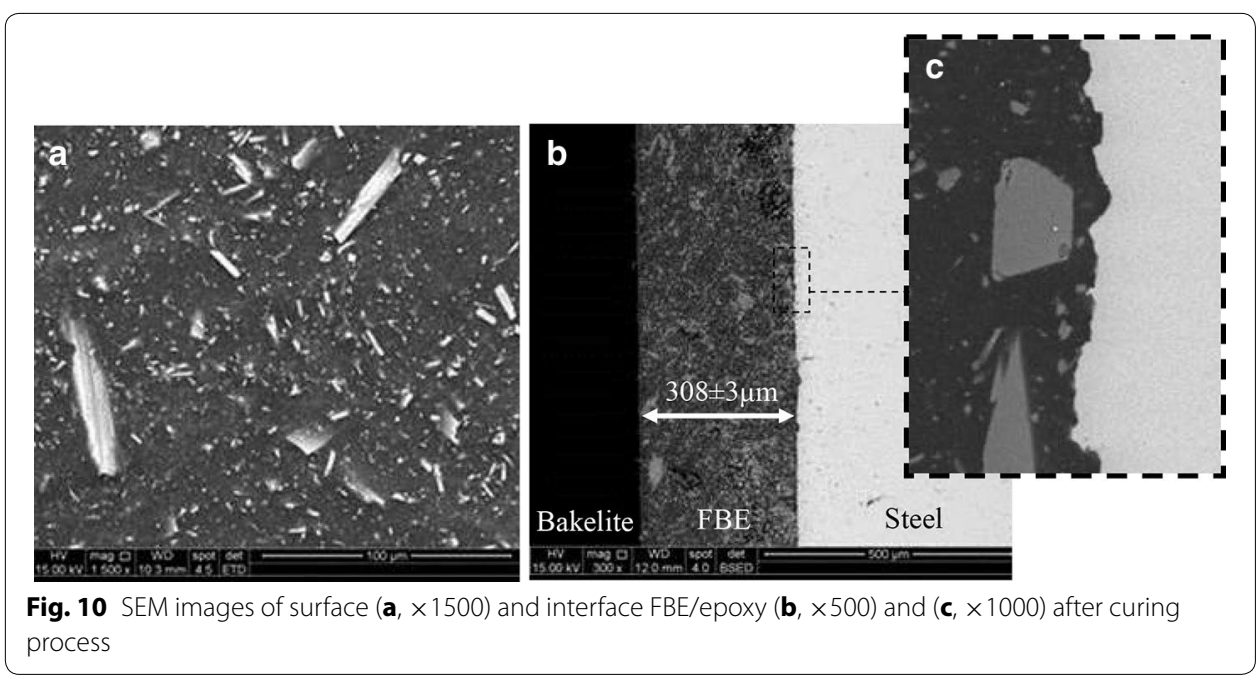

Adhesion tests were initially performed by the Tape Test method that assess the adhesion of a coating to a metallic solid support by applying and removing pressure-sensitive tape over cuts made in the film (ASTM D3359-09) and measuring the amount (\%) of the coating that was removed. Figure 11 shows the results obtained for FBE deposited on bare steel (FBE/bare steel), indicating that no coating was removed by the tape (Class $5 \mathrm{~B}$ [16]). FBE/3-APTMS-modified steel and FBE/3-GPTMS-modified steel presented the same results.

The pull-off strength of the coating was evaluated using portable adhesion testers according to ASTM D4541-09 [17]. In this method, a tension normal to the surface is applied to a loading fixture (dolly) bonded to the coating, and the force is monitored until the system ruptures or the detection limit of the tester is reached. The equipment used in this experiment exerts a maximum pull-off pressure of about $23 \mathrm{MPa}$, which is higher than the minimum specification of Petrobras standards i.e., $17 \mathrm{MPa}$ [40]. None of the systems under evaluation (FBE/bare steel, FBE/3-APTMS-modified steel, and FBE/3-GPTMS-modified steel) failed under tension, indicating that the adherence resistance at the interface coating/solid support is higher than $23 \mathrm{MPa}$. The systems were, then, subjected to shear stress (without loading monitoring) for the removal of the dolly, and the cross-sections of the specimens were observed for failure mode analysis (cohesive failure in FBE coating,
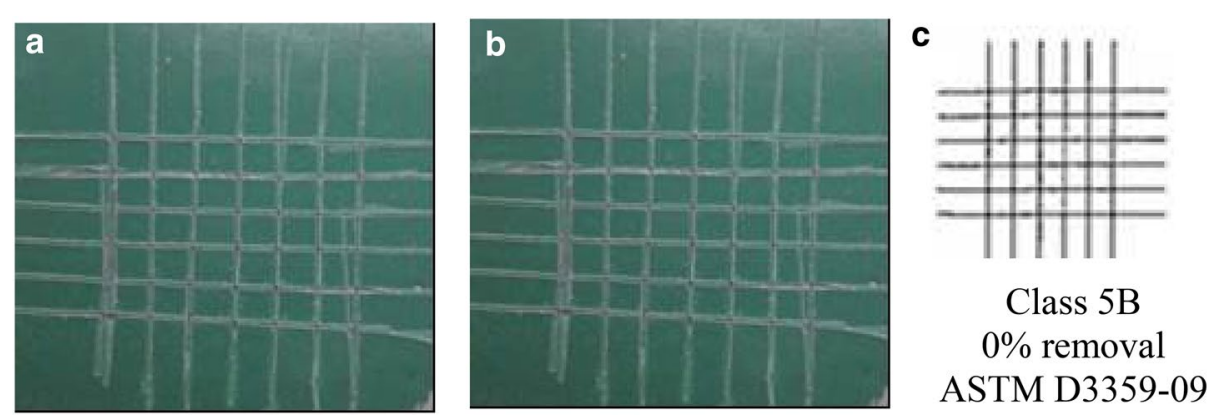

Fig. 11 Typical images obtained for the system epoxy/amine-modified steel surface $\mathbf{a}$ before and $\mathbf{b}$ after adhesion test based on ASTM D3359-09 (tape test). c Results of the experiment based on ASTM D3359-09 
adhesive failure at the interface steel/FBE coating, and cohesive failure in metal substrate). Figure 12 shows images (magnification of $20 \times$ ) of the failure modes. It can clearly be seen a change in the rupture mode from mostly interfacial failure steel/FBE coating to a mixed mode interfacial-cohesive of the FBE for the organosilane modified samples. This behavior was observed to a greater extent for amine-modified steel. The displacement of the rupture from adhesive at steel/FBE interface (bare steel) to cohesive in FBE bulk indicated that the adherence resistance at the interface is higher than at the FBE. Therefore, compared to reference steel and organosilane-modified steel, the improvement in the bond strength of the FBE to the metal support may be associated with interfacial coupling, as previously described in the literature for aminosilanes [13, 29].

Figures 13 and 14 show a schematic representation of the interactions between 3-GPTMS and 3-APTES-silane active surfaces, respectively, and FBE that can enhance
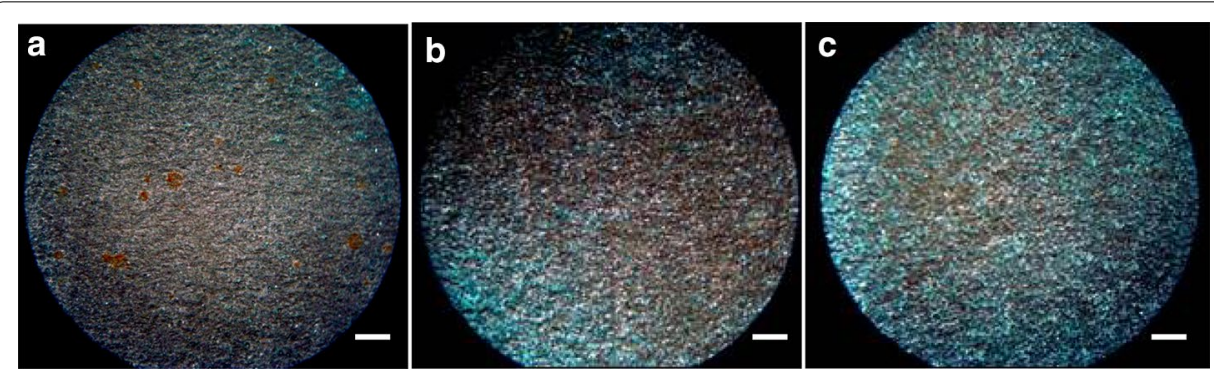

Fig. 12 Rupture mode after removal of the dolly by shear force for cleaned surface (a) glycidoxy-modified surface $(\mathbf{b})$ and amine-modified surface $(\mathbf{c})(\times 40$, scale bar $1 \mathrm{~mm})$

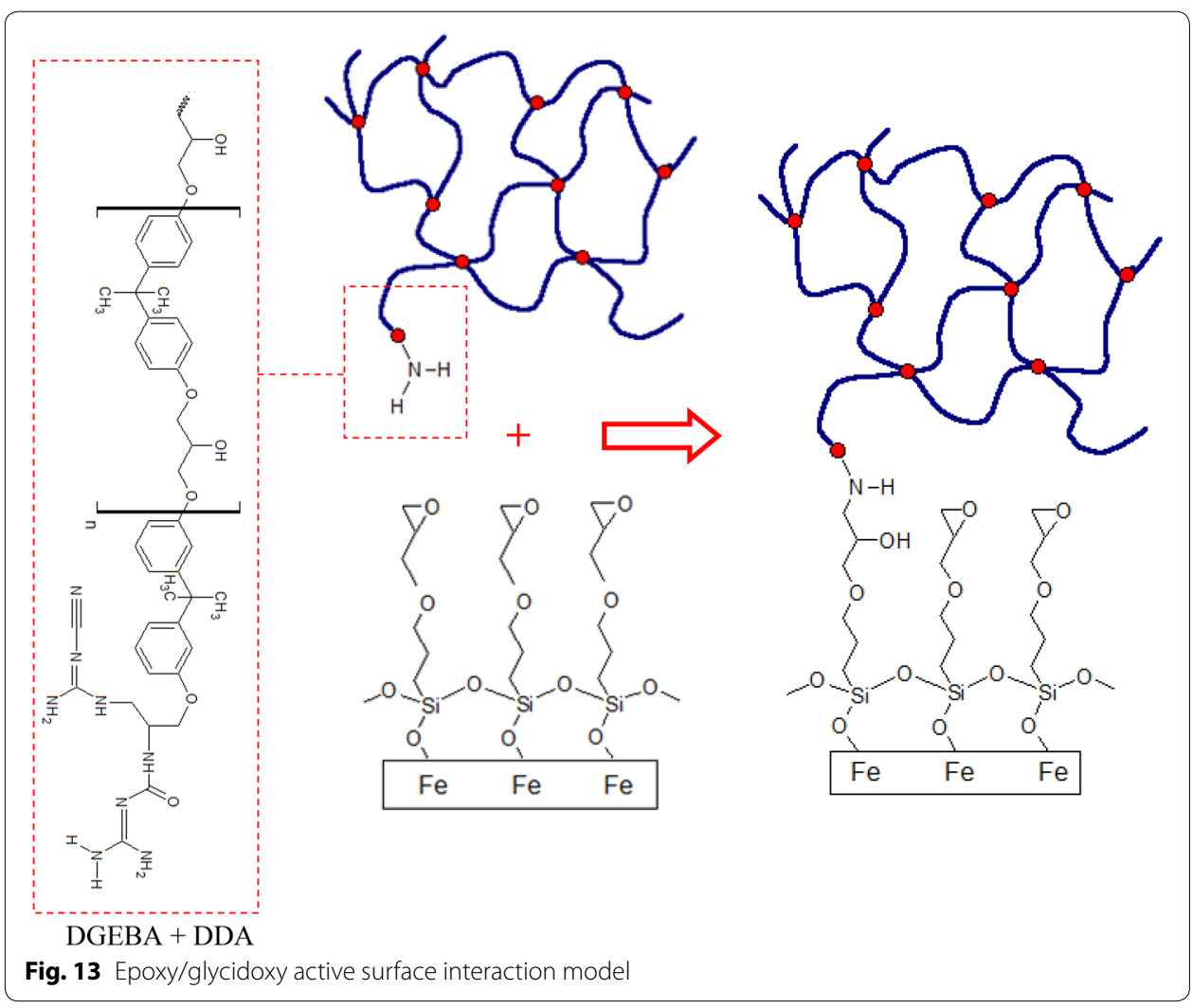




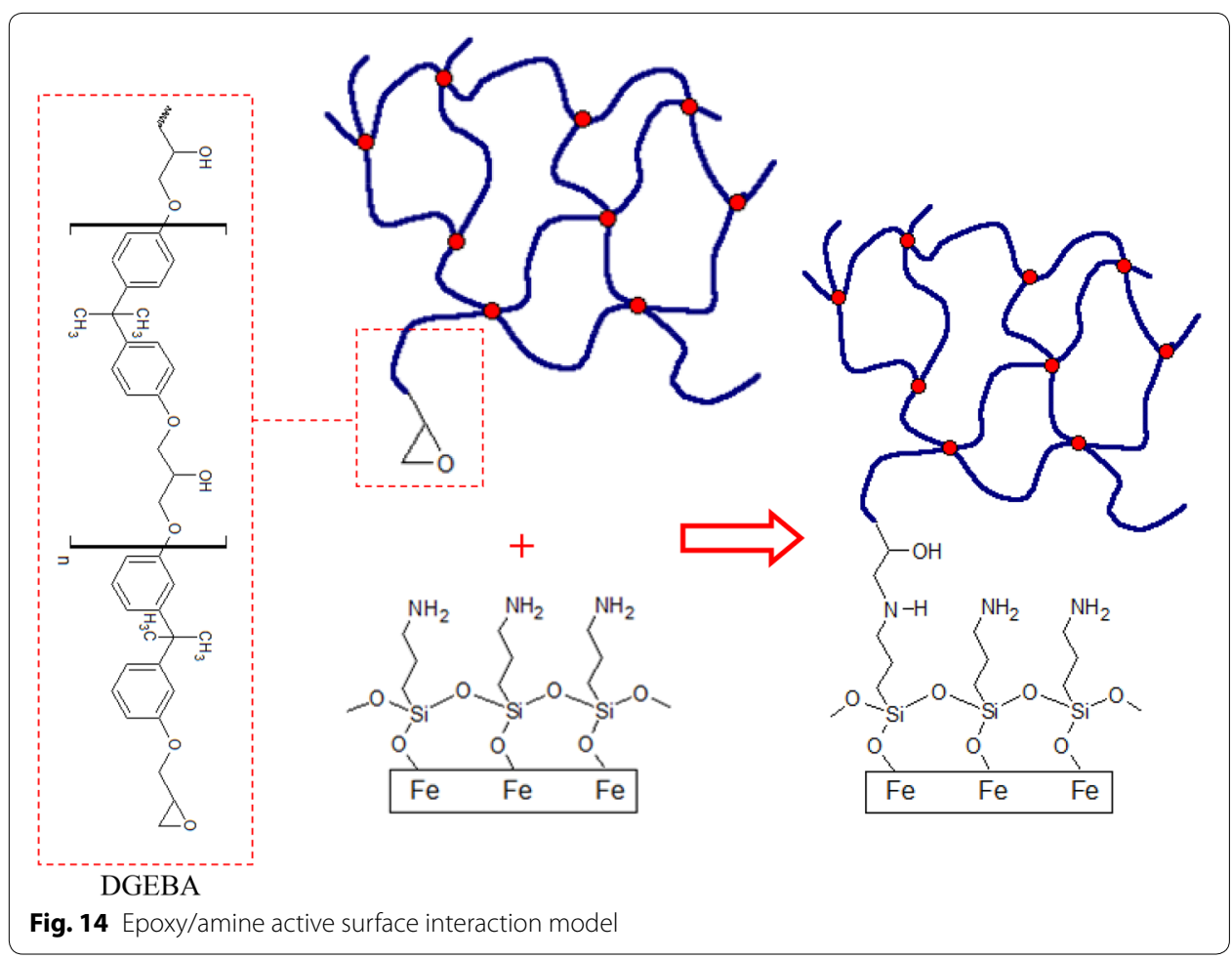

adhesion through the development of covalent bonds between the organofunctional group from surface modifier and the cured FBE.

\section{Conclusions}

The method proposed for organosilane modification of steel solid support was efficient and resulted in homogeneous organically functionalized steel pipelines, as measured by contact angle and FTIR assays. 3-GPTMS and 3-APTES surface modifiers have improved adherence between the steel and fusion bonded epoxy, as detected by the change in the mode of rupture from interfacial to a combined interfacial-cohesive mode for the cured FBE coating. Such adhesion enhancement was attributed the development of new covalent bonds among the cured epoxy chains and organofunctional groups at the interfaces.

\section{Additional files}

Additional file 1: Figure S1. Schematic representation of chemical modification of API $5 L X 42$ steel plate with 3-GPTMS.

Additional file 2: Figure S2. Schematic representation of chemical modification of API $5 L$ X42 steel plate with 3-APTES.

Additional file 3: Figure S3. Schematic representation of FBE coating application on the steel solid support. Additional file 4: Figure S4. EDX spectra of (a) FBE powder (100X, general), (b) Ti-rich phase and (c) calcium silicate phase. 


\section{Acknowledgements}

The authors acknowledge financial support from the following Brazilian research agencies: CAPES (PROEX433/2010;PNPD), FAPEMIG (PPM-00202-13;BCN-TEC 30030/12), CNPq (PQ1B-306306/2014-0; UNIVERSAL-457537/2014-0), and FINEP (CTINFRA-PROINFRA 2008/2010). The authors express their gratitude to P. Trigueiro for the SEM and AFM images.

\section{Competing interests}

The authors declare that they have no competing interests.

Received: 12 November 2015 Accepted: 9 December 2015

Published online: 18 December 2015

\section{References}

1. Liu X, Wang X. The research of oil and gas pipeline corrosion and protection technology. Advan Petrol Explorat Dev. 2014;7:102-5. doi:10.3968/5091.

2. Gielfi GG, Pereira NM, Gomes R, Forniari VCB. User-producer interaction in the Brazilian oil industry: the relationship between petrobras and its suppliers of wet christmas tree. J Technol Manag Innov. 2013;8:117-27. doi:10.4067/ S0718-27242013000300066.

3. Oliveira, A, and DR Rubiano. Innovation in brazilian oil industry. Universidade Federal de Rio de Janeiro, Economics Institute. Rio de Janeiro: UFRJ. 2012.

4. Marín RA. Fundamentals for the development of a world class national oil and gas industry. Revista de Ingeniería. 2014;40:40-9.

5. Forero AB, Milagros MGN, Bott IS. Analysis of the corrosion scales formed on api $5 \mathrm{~L} X 70$ and X80 steel pipe in the presence of $\mathrm{CO}_{2}$. Mater Res. 2014;17:461-71. doi:10.1590/S1516-14392013005000182.

6. Okafor PC, Liu X, Zheng YG. Corrosion inhibition of mild steel by ethylamino imidazoline derivative in $\mathrm{CO}_{2}$-saturated solution. Corros Sci. 2009;51:761-8. doi:10.1016/j.corsci.2009.01.017.

7. Mikhailovskii YN, Marshakov Al, Petrov NA. Monitoring of underground pipeline corrosion condition with sensor $y$ instruments. Prot Met. 1997;33:293-5.

8. Montemor MF. Functional and smart coatings for corrosion protection: a review of recent advances. Surf Coat Technol. 2014;258:17-37. doi:10.1016/j.surfcoat.2014.06.031.

9. Riaz U, Nwaoha C, Ashraf SM. Recent advances in corrosion protective composite coatings based on conducting polymers and natural resource derived polymers. Prog Org Coat. 2014;77:743-56. doi:10.1016/j. porgcoat.2014.01.004.

10. Brylee DBT, Rigoberto CA. Polymeric corrosion inhibitors for the oil and gas industry: design principles and mechanism. React Funct Polym. 2015;95:25-45. doi:10.1016/j.reactfunctpolym.2015.08.006.

11. Rouw AC. Model epoxy powder coatings and their adhesion to steel. Prog Org Coat. 1998;34:181-92. doi:10.1016/ S0300-9440(98)00018-6.

12. Legghe E, Aragon E, Bélec L, Margaillan A, Melot D. Correlation between water diffusion and adhesion loss: Study of an epoxy primer on steel. Prog Org Coat. 2009;66:276-80. doi:10.1016/j.porgcoat.2009.08.001.

13. Diodjo MRT, Belec L, Aragon E, JoliffY, Lanarde L, Perrin FX. Silane coupling agent for attaching fusion-bonded epoxy to steel. ACS Appl Mater Interfac. 2013;5:6751-61. doi:10.1021/am401689s.

14. Jussila T, Ali-Loytty A, Lahtonen K, Hirsimaki M, Valden M. Effect of surface hydroxyl concentration on the bonding and morphology of aminopropylsilane thin films on austenitic stainless steel. Surf Interface Anal. 2010;42:157-64. doi:10.1002/sia.3200.

15. American Petroleum Institute. API 5L: Specification for line pipe. New York: American Petroleum Institute; 2004.

16. ASTM D3359-09. Standard test methods for measuring adhesion by tape test. American Society for Testing and Materials. 2009. doi: 10.1520/D3359-09E02.

17. ASTM D4541-09. Standard test method for pull-off strength of coatings using portable adhesion testers. American Society for Testing and Materials. 2009. doi: 10.1520/D4541-09E01.

18. ASTM A751-14. Standard test methods, practices, and terminology for chemical analysis of steel products. American Society for Testing and Materials. 2014. doi: 10.1520/A0751-14A.

19. ASTM A370-15. 2015. Standard test methods and definitions for mechanical testing of steel products. American Society for Testing and Materials. 2015. doi: 10.1520/A0370-15.

20. Mohsin R, Majid ZA, Yusof MZ. Multiple failures of API $5 \mathrm{~L}$ X42 natural gas pipe: experimental and computational analysis. Eng Fail Anal. 2013;34:10-23. doi:10.1016/j.engfailanal.2013.07.007.

21. Godefroid LB, Cândido LC, Toffolo RVB, Barbosa LHS. Microstructure and mechanical properties of two Api steels for iron ore pipelines. Mater Res. 2014;17:114-20. doi:10.1590/S1516-14392014005000068.

22. Callister WD Jr, Rethwisch DG. Materials science and engineering: an introduction. Rio de Janeiro: LTC; 2012.

23. Tang B, Li D, Fu F, Xu Y, Yu G, Zhang J. A strategy for cleaner pickling: effect, mechanism, and evaluation method of a complex-inhibitor in hydrochloric acid medium. Ind Eng Chem Res Am Chem Soc. 2012;51:2615-21. doi:10.1021/ ie201538m

24. Gentil V. Corrosion. Rio de Janeiro: LTC; 2011.

25. Peres FAS, Teixeira LAC, Yokoyama L, Campos JC, Miguel MAL. Treatment of cooling water with hydrogen peroxide. Quim Nova. 2008;31:1851-5.

26. Misawa T, Asami K, Hashimoto K, Shimodaira S. The mechanism of atmospheric rusting and the protective amorphous rust on low alloy steel. Corros Sci. 1974;14:279-89.

27. Marques ME, Mansur AAP, Mansur HS. Chemical functionalization of surfaces for building three-dimensional engineered biosensors. Appl Surf Sci. 2013;275:347-60. doi:10.1016/j.apsusc.2012.12.099. 
28. Mansur AAP, do Nascimento OL, Vasconcelos WL, Mansur HS. Chemical functionalization of ceramic tile surfaces by silane coupling agents: polymer modified mortar adhesion mechanism implications. Mater Res. 2008;11:293-302. doi:10.1590/S1516-14392008000300011.

29. Doidjo MRT, Belec L, Aragon E, Joliff Y, Lanarde L, Meyer M, Bonnaudet M, Perrin FX. Influence of silane-based treatment on adherence and wet durability of fusion bonded epoxy/steel joints. Prog Org Coat. 2013;76:1765-72. doi:10.1016/j.porgcoat.2013.05.014.

30. Li G, Wang X, Li A, Wang W, Zheng L. Fabrication and adhesive properties of thin organosilane films coated on low carbon steel substrates. J Mater Process Technol. 2007;186:259-64. doi:10.1016/j.surfcoat.2007.04.032.

31. Matinlinna JP, Vallitu PK. Silane based concepts on bonding resin composite to metals. J Contemp Dent Pract. 2007:8:1-8.

32. Kogel JE, Trivedi NC, Barker JM, Frukowski ST. Industrial Minerals \& Rocks: Commodities, Markets, and Uses. Littleton: Society for Mining, Metallurgy, and Exploration Inc; 1994.

33. González, MG, JC Cabanelas, and J Baselga. Applications of ftir on epoxy resins-identification, monitoring the curing process, phase separation and water uptake. Infrared Spectroscopy-Materials Science, Engineering and Technology; 2012. pp 261-284. doi: 10.5772/36323.

34. Gilbert M, Schneider N, MacKnight W. Mechanism of the dicyandiamide/epoxide reaction. Macromolecules. 1991;24:360-9. doi:10.1021/ma00002a004.

35. Anjaneyulu U, Sasikumar S. Bioactive nanocrystalline wollastonite synthesized by sol-gel combustion method by using eggshell waste as calcium source. Bull Mater Sci. 2014;37:207-12. doi:10.1007/s12034-014-0646-5.

36. Nolan NT, Seery MK, Pillai SC. Spectroscopic investigation of the anatase to rutile transformation of sol-gel synthesised $\mathrm{TiO}_{2}$ photocatalysts. J Phys Chem C. 2009;113:16151-7. doi:10.1021/jp904358g.

37. Fata D, Possart W. Aging behavior of a hot-cured epoxy system. J Appl Polym Sci. 2006;99:2726-36. doi:10.1002/ app.22819.

38. Li L, Wu Q, Li S, Wu P. Study of the infrared spectral features of an epoxy curing mechanism. Appl Spectrosc. 2008;62:1129-36. doi:10.1366/000370208786049204.

39. CSA Z245.20-10. Plant-applied external coatings for steel pipe. Canadian Standards Association—CSA. 2010.

40. PETROBRAS I-ET-0000.00-6500-217-PPR-003. External polypropylene anticorrosion coating. Technical Specification of Petrobras. 2015.

\section{Submit your manuscript to a SpringerOpen ${ }^{\circ}$ journal and benefit from:}

- Convenient online submission

- Rigorous peer review

- Immediate publication on acceptance

- Open access: articles freely available online

- High visibility within the field

- Retaining the copyright to your article

Submit your next manuscript at $\boldsymbol{s p r i n g e r o p e n . c o m ~}$ 